\title{
POWERED TWO-WHEELERS IN URBAN ENVIRONMENT: A DETAILED ACCIDENT ANALYSIS
}

\author{
P. VAN ELSLANDE, J.-Y. FOURNIER \& C. PARRAUD \\ The French Institute of Science and Technology for Transport, Spatial Planning, Development and Networks
} (IFSTTAR), France.

\begin{abstract}
The powered two-wheelers (PTWs; moped, motorcycles and scooters) have long been considered as a marginal population, but they developed significantly these last decades in most parts of the world, necessitating a new view concerning them. This is particularly the case in urban areas where their use has increased, notably linked to the possibility they offer to escape the problems of traffic congestion, which attracts an increasingly vast and varied population. In addition, PTWs can also be a good compromise to face in inner-city parking problems. As such, the motorized two wheelers are considered by certain authors as an essential contribution to the urban traffic of tomorrow. However, this view is currently contradicted by the poor level of safety linked to the integration of such vehicles within traffic. As a matter of fact, most epidemiological studies show the overall excess risk to which PTWs are confronted in the traffic system, this risk coming notably from the extreme vulnerability of PTW riders in case of a crash, and relying on some specific accident patterns. This negative effect must be neutralized for PTW to become a true urban mobility tool. The purpose of the present paper is to identify the causes and mechanisms of PTW traffic crashes occurred in town, notably comparing them with those produced in countryside areas. The data rely on a detailed analysis of a sample of 1308 accident police records. The results put emphasis on the difficulties met by PTW users on the road or in the street, and also the difficulties met by car drivers confronted to them. A better knowledge of the specificities and the mechanisms of PTW involvement in injury accidents is viewed as offering a potential improvement of their safety through an adapted urban infrastructure development.
\end{abstract}

Keywords: accident configurations, human error, motorcycling, traffic safety, urban environment.

\section{INTRODUCTION}

In urban areas, a multitude of transport means compete for a limited space. The constant interaction between pedestrians, cyclists, motorcyclists, car drivers and public transport creates situations where people are regularly put at risk as shown by the number of traffic accidents which occur in town. For example, in EU some 11,000 people are killed each year in road traffic crashes happened in urban areas [1]. Moreover, in spite of the overall progress obtained in road safety, urban road deaths tend to take a larger share of the total road safety problem compared to 10 years ago [2]. As a consequence, the restricted space in urban areas must now be used more intelligently and efficiently to face an increased mobility without compromising safety. To achieve this, a dedicated focus on road safety aspects throughout all levels of urban mobility planning is required. Some cities and towns are already well advanced in managing urban road safety issues, others face more difficult challenges, but most of them tend to forget to include powered two-wheelers (PTWs), i.e. moped, motorcycles and scooters, in their mobility planning [1]. However, given their growing presence in town, PTWs must be fully considered as part of urban transport means and this should notably lead to appropriate adjustments in the urban layout aimed at promoting safer interactions with the other road users. In this perspective, a comprehensive knowledge of the mechanisms of PTWs involvement in traffic accidents is useful to precisely understand the difficulty met by the riders when moving in the urban traffic and also by the other town users when they are confronted to them. And such knowledge can be considered as an essential condition to put 
forward significant improvement in traffic safety, notably through adapted urban road development and traffic policy. As mentioned in the Official Journal of the European Union [3], road infrastructure constitutes an important pillar of road safety policy which should make an important contribution to accident reduction. But for that, the design of road environment should be adapted to the capacities and limitations of the different roads and streets users. The present paper aims at putting forward some of these human difficulties and the conditions of their production, as reflected by road crashes involving PTWs in town. A provisional version of this article has been presented in Urban Transport XX [4].

\section{BACKGROUND}

When dealing with motorcycling, two questions must be further considered, the first concerning the role of PTWs within the transport system, notably considering urban development, the second refereeing to the drawbacks linked to the use of this means of mobility in terms of traffic safety.

In the city notably, the use of PTWs can present a number of advantages both at an individual and a societal level. Thanks to their capacity to overtake vehicles, allowing riders to get through most traffic jams, PTWs constitutes an efficient and flexible transport mode with the potential to travel relatively quickly and to have reliable travel times. Moreover, the users of PTW save time when searching for a parking place, by parking, legally or not, very close to their destination. At a societal level, PTWs also provide a number of benefits as they respond to several concerns such as the optimization of the usage of road space and environmental benefits in terms of pollution [5]. It was estimated [6] around 313 million PTWs in operation in the world, with more than three quarters of the PTW fleet in Asia. In large cities, the growing share of PTWs in the motorized fleet is much more marked. In most countries, over the past decade (2001-2010), the motorcycle fleet grew much more rapidly than the passenger car fleet. And it must be considered that this growth is likely to accelerate as the world population increases, and more people recognize the potential economic, mobility and environmental benefits of PTWs. But such a development must not be accompanied by a growth in crashes, injuries and fatalities involving PTWs. The fact is that the potential benefits of PTWs regarding mobility are currently heavily mixed with an overly high societal cost regarding safety. It is essential to study these safety issues both in terms of their aetiology and in terms of solutions for promoting PTWs as a viable transport alternative to traffic congestion.

PTWs are an integral part of the traffic system but at the same time constitute a specific component that deviates somewhat from passenger car standards and needs to be better accommodated and assimilated in the system [7]. Whereas there has been substantial progress in most countries in improving road safety and reducing road mortalities, PTW riders have not benefited at the same pace as car occupants from safety improvements over the last decade. The result is that, regardless of the countries concerned, PTW users are confronted with an excessive risk on the road, which has been qualified as 'unfair' by Elvik [8] insofar as for the same number of kilometres driven they have a much higher risk of being killed or severely injured than car occupants.

Traffic safety results from the interweaving of numerous factors which put in typical different sets of more or less visible actors with regard to the levels of analysis of the dysfunctions. The end-users of the public road network constitute the direct actors, in charge of the micro-control of the traffic (drivers, riders, pedestrians, etc.). But this use joins in an overall context which is under the responsibility of the designers, the manufacturers and the 
administrators who are involved in the macro-regulation of this system [9]. The 'accidents of the city' are thus analysed here under the angle of this double determination of road safety problems, searching to put forward not only the drivers' errors and other failures, but also the upstream factors originating them.

The level of risk underlying motorcycling is influenced by many factors, not only in terms of secondary safety (protection) but also in terms of primary safety (prevention). A first general factor of accident proneness is the intrinsic difficulty to control a PTW, due to the necessity to maintain the balance, its lower friction capacity and its greater sensibility to environmental perturbations (wind, gravel, any change in road surface, etc.), which may destabilize the vehicle. Another influential risk is the domination of cars and larger vehicles in traffic, and the fact that the traffic system has mainly been designed for these vehicles. As a consequence, the traffic system now requires an adaptation towards the integration of the growing volume of PTWs. In that purpose, it is necessary to thoroughly study the difficulties met by the riders and the other road users facing them, as they are expressed notably in traffic accidents. And this is particularly relevant in urban environment where PTW traffic is a growing issue. The fact is that $42 \%$ of the motorcycle rider fatalities and $58 \%$ of the moped riders fatalities in Europe in 2008 occurred inside urban areas. These proportions are considerably larger than for car occupants (23\%) [10].

\section{METHOD}

As mentioned by Sgarra et al. [11], quantitative safety indicators are not sufficient to fully understand the accident phenomena. More in-depth accident analysis offers the capacity to put forward the needs of road users by diagnosing the malfunctions occurring in a system and the lacks in its defences [12]. It has been typically used in the road transport domain to study the influence of certain factors such as speed, inexperience, alcohol, etc., on crash production [13]. A previous study [14] was aimed at identifying the specific characteristics of passenger car crashes occurred in urban environments, allowing to better understand their mechanisms and specificities in comparison to crashes occurring in the open countryside. Face to the increase traffic of PTWs, notably in town, the same question is presently addressed to the specificity of crash patterns for this kind of vehicles. More precisely, the object of the present work is the detailed analysis of motorized two-wheelers accidents occurred in urban area, for an improvement of the knowledge on their genesis, their determiners and specificities, from the point of view of the difficulties encountered by the drivers as revealed by accident data. The knowledge stemming from such an analysis will be considered as essential for a better adaptation of the urban planning to the road users' capacities and limits.

\subsection{Data and models}

The research work is based on a detailed analysis of a representative sample of 1080 police reports of road crashes occurred in town, involving at least one PTW. For comparison purposes, this sample will be sometimes confronted with a control group of 228 PTW crashes occurred in the countryside. The analysis was conducted in a way to extracting systematic information on: the typical accident configurations, the combinations of human-vehicleenvironment factors involved and the consecutive drivers' errors and other human failures involved in the accident process.

The two samples were built from a random sampling of accident cases gathered at the national level by IFSTTAR Institute (France) for research purposes, this sampling being rep- 
resentative of the injury accidents reported in France by the Police services. The accident reports include statements by the persons involved and the witnesses, a map of the accident site with the situation of the collision point and position of the vehicles after the crash, medical data on the injuries, sometimes photographs of the site, etc.

The analysis made use of both an accident phase model [15] allowing the segmentation of the accident process in a systematic way; and a human failure model (HFF) allowing the classification of the driving functional failures (i.e. human errors and capacity exceeding) found in traffic accident and of the factors of these failures [16]. The HFF model distinguishes five major functional categories within which can be identified the incapacity of a function (perception, diagnosis, prognosis, decision, execution of action) to overcome a difficulty encountered by the driver (Table 2). Perception failures refer to the no detection or the non-identification of a crucial element of the driving scene. Diagnosis failures encompass a poor evaluation (of an incoming speed, of a time/space gap) or a poor understanding of the present situation. Prognosis failures deal with the wrong anticipation of the present situation evolution, or a wrong prevision of a still non-visible event to come. Decision failures cover the undertaking of a manoeuvre at a wrong place and time. And execution failures state the maladjusted controls of the vehicle. A sixth heading deals more with a problem of general aptitude to drive than the specific capacity to handle a difficulty: these 'generalized failures' correspond to an alteration to the entire functional chain (i.e. on the perceptive, cognitive and psychomotor levels) making the driver unable to manage the slightest difficulty encountered on his route (e.g. falling asleep). These six categories of failures are delineated in 20 types, which will be further detailed in the results part, as will also be detailed the different factors of these human failures and the level of involvement of the different drivers concerned.

\subsection{Coding reliability and statistical analysis of the results}

To check the reproducibility of the coding method used, an inter-rate reliability was tested in a previous study applying the same method on another sample of crash files [17]. The analysis of the reliability rate was performed on the basis of the comparison between the coding in parallel of 100 crash reports by two teams of coders. The proportion of inter-expert agreement was measured for the variables 'categories of failures' and the 'types of failures' identified for each driver studied, and also for the factors of these driving failures. A Cohen's Kappa coefficient was measured for each observed proportion of agreement, and the scale proposed by Landis and Koch [18] was used to test the validity of the results. These results gave a rate of agreement above $80 \%$ for the variables 'categories of failures' and 'types of failures' (Kappa coefficient between 0.73 and 0.86), which correspond to a 'good' up to 'excellent' agreement according to the Landis and Koch scale. Regarding the variables 'factors of failures' (from 1 to 5 items identified, depending on the case), the agreement rate was $94 \%$ for the first item and $70.5 \%$ for the second one with Kappa values of 0.94 and 0.67 corresponding to agreements considered 'excellent' and 'good', respectively. The agreement then tends to decrease for the following explanatory elements, which can be explained by the fact that they correspond to more secondary factors with regard to the accident generating process.

Statistical analyses of the results were performed to determine whether or not the distribution of the human failures and the levels of involvement were different between the groups of comparison (Urban versus Countryside; Moped versus Light motorcycle versus 
Heavy motorcycle). These hypotheses were tested with a chi-square test for independence. The p-values given in the tables for this chi-square indicate if there is a significant difference between the groups. A p-value $<0.05$ will indicate a significant difference, and a p-value $<0.01$ will indicate a highly significant difference between the groups considered.

\section{RESULTS}

The present section will deliver the essential results by first comparing urban versus countryside crashes, and secondly by focusing on the urban ones with the view to investigate the eventual differences characterizing three main categories of PTWs: (1) mopeds with an engine displacement $<50 \mathrm{~cm}^{3}$, (2) light motorcycles with a displacement $<125 \mathrm{~cm}^{3}$, and (3) heavy motorcycles with a displacement above $125 \mathrm{~cm}^{3}$.

\subsection{Level of involvement of PTW riders in urban versus countryside crashes}

The variable 'level of involvement' described in this section defines the role played by each protagonist involved in the genesis of the accident. Close to the notion of 'responsibility', it differs nevertheless from this latter by the reference not to a legal code but to a strictly behavioural reference, with the purpose to better understand the whole accident process. The first modality, 'Primary contributing', designates the drivers who are at the origin of the conflict that ended into a crash. It must be noted that, at the difference from the paper presented in Urban Transport XX [4] where only one road user could be primary active, in the present analysis it was considered conceivable that two protagonists of a same crash were classified under this label, as far as they both initiated a manoeuvre on the path of the other one (e.g. when a car turns across the path of a PTW rider who decides to overtake it). The second modality, 'Secondary contributing' relates to drivers who contribute to the non-resolution of the conflict generated by not trying to prevent or react in spite of alarming indications. The 'No contributing' modality includes all the drivers who have been confronted to a conflict without having the possibility to see it in advance nor to react on time. Table 1 shows a significant difference between urban and non-urban crashes with a higher tendency of riders to originate the accident process in the latter situation. On the opposite, the PTW riders show a stronger tendency to act as secondary contributors in crashes occurring in town by no preventing a predictable conflict or not reacting to it, relying on the anticipated resolution of the situation by the protagonist. The results show no difference between urban and non-urban crashes for the 'no-contributing' condition.

Table 1: PTW riders' level of involvement in urban and countryside crashes.

\begin{tabular}{lcc}
\hline & Urban & Non-urban \\
\hline Primary contributing & $54.4 \%$ & $64.0 \%^{* *}$ \\
Secondary contributing & $34.8 \%^{* *}$ & $25.0 \%$ \\
No contributing & $10.6 \%$ & $10.9 \%$ \\
Total (n) & 1080 & 228 \\
\hline
\end{tabular}

\footnotetext{
**Highly statistically significant difference (p-value $<0.01)$.
} 


\subsection{PTW riders failures in urban versus countryside areas}

The determination of human driving failures from police records requires not only expertise from the analysts but also enough reliable data. When the data were not judged clear enough to state the failure with enough confidence, the case was coded 'undetermined'. This explains why the samples of analysis in this section (cf. Table 2) are reduced from the original ones.

When comparing urban and non-urban environments crashes, a distinction appears in the categories of human functional failures to which PTW riders are more subject along the accident generating processes. As seen in Table 2, PTW riders are significantly more subject in urban environment than in the countryside to failures at the prognosis level (41\% versus $29.3 \%$ ); this refers to the anticipation and prevision functions which seem to be more affected in urban traffic. On the opposite, riders involved in an accident occurring in the countryside are showing far more deficiencies at the execution level of the driving process $(26.0 \%$ versus $12.1 \%$ ); this refer to the operation controls (steering, braking, etc.), which appear more critical in the countryside where the travelling speeds are higher. The other categories of driving failures show no significant difference.

But when going more in detail, even if no general distinction was found at the Perception category level, one specific type of perceptive failure is typically represented in urban area: the 'Non-detection in a situation of limited visibility'. This can be explained by the prevalence of obstacles to the visibility (buildings, vehicles, signalization, etc.) in such environment. Dealing with the difference noted at the Prognosis level, there is also one specific failure which stands out quite particularly in town: the 'Expectation by default of no manoeuvre by another user', characterizing nearly one-third of the riders' failures in urban accidents. The process of this failure is complex insofar as it combines some factors dealing with the rider himself (feeling of right of way, illusion of visibility) and the opposite road users who fail to notice the oncoming PTW. Finally, the bigger representation of PTW riders' execution failures found in non-urban crashes essentially corresponds to the 'Poor controllability of the vehicle when faced with an external disturbance', such as a tight bend, a wet road, etc., leading the riders to lose the control of their machine.

Such differences attest that, through the layout design and the traffic interactions supported, the road environment has an incidence on the difficulties met by PTW riders on the road and the street and the resulting human failures to which they are subject. Seen on the

Table 2: Distribution of riders' failure categories for urban and countryside crashes.

\begin{tabular}{lcc}
\hline & Urban & Non-urban \\
\hline Perception failure (detection, identification) & $25.6 \%$ & $22.1 \%$ \\
Diagnosis failure (evaluation, understanding) & $9.6 \%$ & $8.2 \%$ \\
Prognosis failure (anticipation, prevision) & $41.0 \%{ }^{* *}$ & $29.3 \%$ \\
Decision failure (when undertaking a manoeuvre) & $8.4 \%$ & $9.6 \%$ \\
Execution failure (control of action) & $12.1 \%$ & $26.0 \% * *$ \\
Generalized failure (from perception to execution) & $3.2 \%$ & $4.8 \%$ \\
Total (n) & 995 & 208 \\
\hline
\end{tabular}

\footnotetext{
**Highly statistically significant difference (p-value $<0.01)$.
} 
other way round, this suggests a potential gain offered by a design of the street better incorporating the specificity of PTWs.

\subsection{Car drivers failures when confronted to a PTW}

An important proportion of PTW traffic crashes involve a passenger car. Therefore, it is important to understand also the kind of difficulties met by car drivers when encountering a PTW with the purpose to find ways to reduce these difficulties. There is a huge amount of literature showing that car drivers are particularly prone to perception failures as regard as PTWs. This result is found again in the cases studied (Table 3), and even a little bit more when the crash occurs in an urban area $(65.2 \%$ versus $58.4 \%)$, due to the numerous potential obstacles to visibility, whereas fixed or moving, found in town, and to the multiplicity of information to gather at the same time. The difference is not statistically significant in the comparison between urban and non-urban environment. However, the huge amount of perceptive problems contributing to crashes in town (65.2\% of car drivers' failures) attests the potential capacity of urban development to promote a better safety of interaction between car drivers and PTWs. But for that, the circumstances behind these perceptive difficulties need to be further explained, as it will be done in Section 4.5 describing the most typical PTW accident configurations found in town.

Three categories of car drivers' failures vis-à-vis PTWs, even if less represented as a whole than the perceptive problems, show a significant difference between urban and non-urban environment. The first one deals with diagnosis problems which are more typically found in the countryside. These diagnosis failures relate more precisely to the poor evaluation of the incoming speed of the PTW by the car driver. The second category of car drivers' failures differentiating urban and non-urban car versus PTW crashes correspond to decision problems, with a specific failure corresponding to the engagement of an inadequate manoeuvre by automatism or ripple effect (i.e. by following another car), particularly more found in urban area. The third differentiating problem is linked to execution failures which represent the poor control of the vehicle by the car driver (e.g. maintaining the vehicle on its correct course), more found in non-urban roads where driving speed is higher.

Table 3: Distribution of car drivers' failures when meeting a PTW in urban and countryside crashes.

\begin{tabular}{lcc}
\hline & Urban & Non-urban \\
\hline Perception & $65.2 \%$ & $58.4 \%$ \\
Diagnosis & $5.7 \%$ & $14.4 \% * *$ \\
Prognosis & $9.2 \%$ & $9.6 \%$ \\
Decision & $17.0 \% *$ & $11.2 \%$ \\
Execution & $1.4 \%$ & $4.8 \% *$ \\
Generalized & $1.4 \%$ & $1.6 \%$ \\
Total (n) & 770 & 125 \\
\hline
\end{tabular}

*Statistically significant difference (p-value $<0.05)$.

${ }^{* *}$ Highly statistically significant difference (p-value $\left.<0.01\right)$. 


\subsection{Riders' failures in town according to the type of PTW}

If we now concentrate on urban crashes, a question remains to whether the different types of PTWs (moped, light motorcycles, heavy motorcycles) encounter the same difficulties in the traffic or if there is a specificity of the safety problems met by some of them. As expressed on Table 4, a first particularity comes from the Moped category, which shows significantly more riders primary contributing to their accident $(64.9 \%)$ than the two other categories that are Light motorcycles and Heavy motorcycles (respectively $48.5 \%$ and $48.6 \%$ ). These two last types of PTWs are far more concerned by a secondary contribution to the non-resolution of the conflict generated by another road user, who is most of the time a car driver. Moped riders are also differentiating from the other types of PTWs by their lower involvement in crashes where they do not contribute.

Another difference between the types of PTWs crashes occurred in urban areas addresses the question of human functional failures (Table 5). Moped riders once again are differentiated from the others, notably by showing significantly more failures in Perception (31.8\% of their failures) with a strong representation of poor and hasty information gathering. They are also singularized by Decision problems $(11.4 \%)$ and more particularly by putting forward risky manoeuvres. Motorcycles, whether Light or Heavy, are proportionally far more subject to

Table 4: Riders' level of involvement for different types of PTWs.

\begin{tabular}{lccc}
\hline & Moped & Light motorcycle & Heavy motorcycle \\
\hline Primary contributing & $64.9 \% * *$ & $48.5 \%$ & $48.6 \%$ \\
Secondary contributing & $28.2 \% * *$ & $38.7 \%$ & $38.5 \%$ \\
No contributing & $6.9 \% *$ & $12.8 \%$ & $12.8 \%$ \\
Total (n) & 390 & 326 & 358 \\
\hline
\end{tabular}

* Statistically significant difference (p-value $<0.05)$.

${ }^{* *}$ Highly statistically significant difference (p-value $\left.<0.01\right)$.

Table 5: Distribution of riders' failure categories for different types of PTWs.

\begin{tabular}{lccc}
\hline & Moped & Light motorcycle & Heavy motorcycle \\
\hline Perception & $31.8 \% * *$ & $22.9 \%$ & $21.4 \%$ \\
Diagnosis & $11.4 \%$ & $7.0 \%$ & $9.9 \%$ \\
Prognosis & $29.1 \%{ }^{* *}$ & $51.5 \%$ & $44.7 \%$ \\
Decision & $11.4 \%^{*}$ & $6.6 \%$ & $6.8 \%$ \\
Execution & $12.0 \%$ & $9.6 \%$ & $14.3 \%$ \\
Generalized & $4.3 \%$ & $2.3 \%$ & $2.8 \%$ \\
Total $(\mathrm{n})$ & 368 & 301 & 322 \\
\hline
\end{tabular}

* Statistically significant difference ( $\mathrm{p}$-value $<0.05)$.

**Highly statistically significant difference (p-value $<0.01)$. 
Table 6: Distribution of riders' age for different types of PTWs.

\begin{tabular}{lccc}
\hline & Moped & Light motorcycle & Heavy motorcycle \\
\hline Age mean (standard deviation) & $23.3(10.4)$ & $36.6(11.5)$ & $35.4(10.6)$ \\
\hline
\end{tabular}

Prognosis failures (51.5\% and $44.7 \%$ ) often corresponding to a too strong confidence in their own expectation about events to occur and their anticipation about the evolution of driving situations, relying notably on a strong feeling of right of way [19]. In fact, their prognosis is often contradicted by the unexpected manoeuvre performed by car drivers who fail to perceive them.

One overall explanation of the differences between mopeds and the other kinds of PTWs refers to the age of the riders. As shown in Table 6, the distribution of riders' age in the sample is not identical for the different categories of PTWs, moped riders being significantly younger than the other riders. Such a difference can account, for example, for the wrong decisions taken by moped riders notably regarding risky manoeuvres undertaken. The relative lack of experience characterizing the youngest can also explain their weakness regarding perception, in relation with a lower ability to develop efficient information gathering patterns.

On the opposite, an important level of experience may have the side effect to promote a too strong confidence of the riders in their own anticipations, as it is the case for the other types of PTW riders, and make them powerless when confronted to unexpected manoeuvres from the others road users. As a matter of act, as already mentioned, there is often an interaction in the reciprocal failures committed by the different protagonists of an accident process, which is useful to identify as they will be in the following section under the label of typical accident configurations.

\subsection{Most typical PTW accident configurations found in the city sample}

Typical accident configurations have the advantage to present in a synthesized way the major mechanisms extracted from a case-by-case analysis. They are built on the basis of an overall similarity regarding the chain of events, malfunctions and causal relationships. The identification of the most frequent typical accident configurations gives an immediate indication on the problems to solve, notably through road design and traffic policy [20].

Ten categories of typical crash configurations were put forward from the accident data, allowing to aggregating $83 \%$ of the whole sample (Table 7), the other cases not showing recurrence enough to be aggregated in robust and meaningful configurations. Most of the established typical crashes configurations correspond to intersections situations, where a PTW and a passenger car are confronted while one of them either exits from (category A) or enters in (category B) the traffic flow. These situations encompass more than $56 \%$ of the cases. Among them, three more specific types of crashes configurations massively characterize the safety problems met by PTWs inside the urban traffic, representing together more than $20 \%$ of the accident sample. They are summarized hereafter. More detailed information on PTW crash-producing scenarios can be found in Jaffard and Van Elslande [19], and Clabaux [20]. 
Table 7: Distribution of typical crash configurations categories

\begin{tabular}{lc}
\hline Categories of typical crash configurations & $\%$ \\
\hline A: Situations of entrance in the traffic flow & 23.4 \\
B: Situation of exit from the traffic flow & 33.2 \\
C: Lane changing & 7.3 \\
D: Use or intrusion of the opposite way & 2.1 \\
E: Poor control of the inter-distance between vehicles & 7.7 \\
F: Poor control of trajectory & 11.2 \\
G: Meeting an obstacle on the road & 3.2 \\
H: Aberrant manoeuvre & 2.4 \\
I: With pedestrians & 8.8 \\
J: Others & 0.7 \\
\hline
\end{tabular}

\subsubsection{Configuration B.1.1: a car driver turns across an oncoming PTW}

This configuration represents $8.7 \%$ of PTW urban crashes. The PTW rides on a priority axis. A car driver, arriving in the opposite way and wishing to turn across the road, does not detect the PTW in spite of no obstacle to visibility. The rider, convinced to be seen and confident in his right of way feeling keeps his momentum. The car driver engages his change of direction and cuts in front of the PTW rider who has no more the possibility of making anything to avoid the crash (Fig. 1a). In this configuration, most car drivers are primary active as a consequence of a perceptive failure and most riders are secondary contributing following their prognosis failure.

\subsubsection{Configuration B.1.3: a PTW rider overtakes a car turning across}

This configuration represents $7.8 \%$ of PTW urban crashes. The PTW circulates behind a passenger car which slows down with or without its indicator on. The PTW rider decides to overtake the car, either because he did not anticipate the manoeuvre, or he is convinced to have been seen, or thinks he will master the situation if it is not the case. At the same moment, the passenger car makes a change of direction in intersection or in private access, on the trajectory of the PTW (Fig. 1b). In this configuration, most drivers (81\%) and riders (82\%) are considered as primary active as far as they both put forward a manoeuvre on the path of the other. Once again, in most of the cases (95\%) car drivers commit a perceptive failure not seeing the approaching PTW from the rear, while PTW riders are more concerned with failures of diagnosis (27\%), not understanding the manoeuvre of the car, and mainly failures in prognosis (52\%), anticipating that the car driver will wait before turning.

\subsubsection{Configuration A.1.7: a PTW filtering versus a car crossing the road}

The third most typical configuration represents $4.3 \%$ of the cases. A PTW rider is filtering or overtaking along a line of vehicles going slow. A vehicle of the line stops or slows down to allow a non-priority crossing car to pass of him (at an intersection, a private road or a car park). This car driver starts to cross the road and do not detect the PTW masked by the line of vehicles. In the same way, the PTW rider does not detect the car crossing also masked by the line of vehicles (Fig. 1c). Both drivers and riders are primary active, the former failing to 


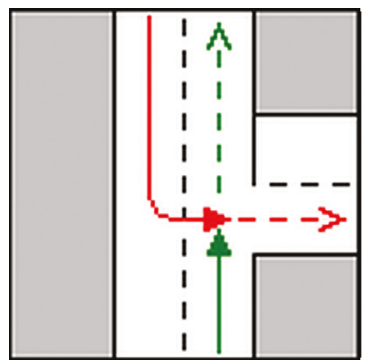

(a)

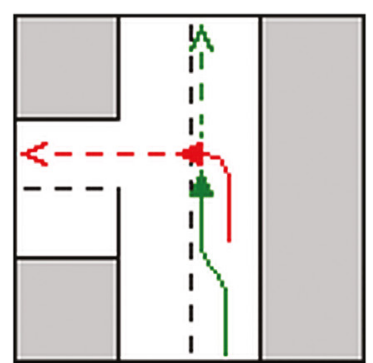

(b)

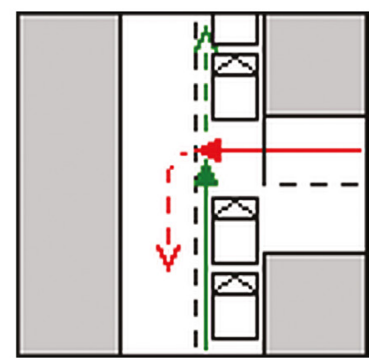

(c)

Figure 1: Main typical PTW urban accident configurations (green: PTW and red: other vehicle).

perceive the PTW, the later being concerned both by a problem of decision (when overtaking in critical conditions) and a problem of perception of the car crossing.

These three main typical configurations well illustrate an important stake in PTW road safety and even more particularly in urban traffic. They present the particularity to all involved contradictory movements of a PTW and a passenger car occurring at an intersection of streets which leads them to an antagonistic path, ending into a conflict; reminding that the victim of this conflict is nearly systematically the PTW rider, due to his intrinsic frailty. The human failures that can be inferred from the detailed case-by-case analysis stress the importance to promote efficient reciprocal perception, understanding and anticipation between road users in their interactions, notably thanks to infrastructure improvement, as seen in the discussion below.

\section{DISCUSSION}

The classification of cases as 'urban accidents' in the database corresponds to road crashes that take place between the panels of entrance and city exit. It must be considered that many of these crashes are consequently occurring on so-called 'transition' zones that are in reality often closer to the characteristics of open country than the city ones. This has probably attenuated some differences that have been identified between the urban and the non-urban samples. The detailed analysis performed on the whole sample nevertheless brings out a number of major points that specify the generating process of accidents occurring in urban areas. These results are therefore useful to consider with a view to improving road safety in the city.

Of course, the road infrastructure cannot be viewed as a systematic and direct cause of human failures. But road design plays at least an indirect role on the complexity of the task devoted to the different road users, through the movements induced or permitted, through the visibility offered, through the quantity of information to integrate, etc. By such, adapting this road design in a way to integrate human frailty constitutes an essential lever of road safety. This involves first the prevention of human error with the development of road users' friendly roads, e.g. traffic calming, efficient use of roundabouts, simplified situations, etc. This encompasses of course also the protection of these road users against injury in case of a failure in their attempt to adapt to traffic situations, e.g. suppression of aggressive obstacles.

In such an overall vision, PTWs partly benefit from the safety improvements made for passenger cars, notably when dealing with traffic calming measures, which confront them 
with interactions at lower speed, minimizing the risk of a conflict and maximizing the possibility to react on time to it. But due to their intrinsic specificity and the particularity of their crashes scenarios, PTW safety also asks for tailored measures. As seen from our results, this would particularly concern the perceptive problems met by car drivers and the prognosis difficulties met by cars drivers when the encounter each others.

It has been shown in previous studies [21,22] that the perceptive problems met by car drivers vis-à-vis PTWs are - independently of the road environment - significantly higher than vis-à-vis others road users. This illustrates the utility to favour a better perception of this category of vehicles. This is excessively the case in town where PTWs are more and more present, and where these perceptive problems are found in the present study to account for more than $65 \%$ of car drivers' failures when confronted to these two-wheeled vehicles. The description of the different accident processes involving such perception problems can help in defining specific adjustments of urban design and traffic regulation.

Among such developments can be promoted not only the treatment of obstacles to visibility, the suppression of useless sources of distraction (e.g. advertisements) and complicated infrastructure but also classical traffic calming measures as far as the speed of motorcycles has been proved to have an effect on their detectability $[23,24]$.

Another point to consider is the strong connection between the prognosis problems met by PTW riders (in a proportion significantly higher in town) and the perceptive problems met by car drivers as shown by the accident scenarios. Indeed, when car drivers do not detect an incoming PTW, they engage unexpected manoeuvre which in turn mislead the expectations of PTW riders. As a consequence of this interaction in error production, there would be a double beneficial effect in promoting a better reciprocal perception between PTW riders and car drivers: the first one leading to minimize the detection failures by car drivers and the second one to diminish the prognosis failures by PTW riders.

Beyond this crucial question of reciprocal visibility, the problems met by PTW riders may lead to more specific measures typically addressing them. The most radical measures refers to segregate lanes, which has been proved to be an efficient solution to protect riders from conflicts with cars and trucks, the greatest benefit of this solution being got when the PTW traffic overcome a certain level (according to Radin Umar, Mackay and Hills [25]: 15,000 vehicles a day with a proportion between $20 \%$ and $30 \%$ of PTWs in the traffic). But less massive solutions can also be promoted to avoid critical interactions with cars in town, such as replacing intersections, known to be detrimental to PTWs, with roundabouts, but considering the necessity to adapt them to avoid PTWs single vehicle crashes when negotiating them [26].

\section{CONCLUSION}

Every system conceived and dedicated to a human usage must be elaborated in a way to conform to human characteristics, in a way to make an efficient use of their capacities without exceeding their limits and taking into account their eventual weaknesses. It is a founding principle of ergonomics that can be applied to the traffic domain. Road environment is both a physical medium that ensures mobility and the background for understanding the events that occur while driving. The way in which it is adapted to its users has a considerable influence on their behaviour, especially in urban areas where design is over determinant.

Urban management policies have changed over the past 20 years and now attempt to take into account and satisfy numerous concerns (safety, quality of life, etc.). However, both the number and severity of urban traffic accidents remain high and this is specifically the case when dealing with PTWs, which suffer from a general underestimation of their role in traffic 
[11]. The fact is that road and traffic management have traditionally been designed for fourwheel vehicles. In some cases, these are not properly adapted for PTW and are not promoting safe interactions with other road users. Much could be done to harmonize the mobility and safety of PTWs with the other road users. Infrastructure should be improved with the promotion of a better mutual visibility, the development of self-explaining roads and traffic calming measures to guide drivers and riders to adopt appropriate speeds and behaviour, and PTW friendly equipment in case of a collision. As a matter of fact, the role of infrastructure is not limited to protection as might suggest a too brief definition of the 'safe system' approach [27]. The traffic organization and the road system design and management must promote the tools for efficient prevention of safety problems for every road users, not only to put on the right defences when these problems do occur.

\section{REFERENCES}

[1] ETSC, Integrating Safety into the EU's Urban Transport Policy, Brussels, Belgium: European Transport Safety Council, 2013.

[2] ITF/OECD, Improving Safety for Motorcycles, Scooters and Mopeds Riders, OECD: Paris, 2015.

[3] Official Journal of the European Union of 19 November 2008 on Road infrastructure safety management, available at: http://eur-lex.europa.eu (accessed 13 April 2015).

[4] Van Elslande, P., Fournier, J.-Y. \& Parraud, C., Safety problems met by powered twowheelers in urban traffic. WIT Transactions on the Built Environment, 138, pp.479-490, 2014. doi: http://dx.doi.org/10.2495/UT140401

[5] Ducreux, B.O., Powered Two Wheelers Compared With Cars: Driving Dynamics, Fuel Consumption and Exhaust Emissions in Daily Use, Ademe: Valbonne, 2008.

[6] Rogers, N., Trends in Motorcycles Fleet Worldwide, available at: http://www.internationaltransportforum.org (accessed 10 November 2014).

[7] Van Elslande, P. \& Elvik, R., Powered two-wheelers within the traffic system. Accident Analysis and Prevention, 49, pp. 1-4, 2012. doi: http://dx.doi.org/10.1016/j. aap.2012.09.007

[8] Elvik, R., Benefits and fairness: are the high risks faced by motorcyclists fair? (Chapter 1). Les deux-roues motorisés: nouvelles connaissances et besoins de recherche, ed. $\mathrm{P}$. Van Elslande, Les collections de l'Inrets: Bron, pp. 17-26, 2009.

[9] Fleury, D., Urban safety management: how to deal with complexity. Advances in Complex Systems, 10, pp. 327-338, 2007. doi: http://dx.doi.org/10.1142/S0219525907001380

[10] DACOTA, Traffic safety basic fact 2010: motorcycles and mopeds, available at: www. dacota-project.eu/index.html (accessed 15 April 2015).

[11] Sgarra, V., Di Mascio, P., Corazza, M.V. \& Musso, A., An application of ITS devices for powered two-wheelers safety analysis: the Rome case study. Advances in Transportation Studies, 33, pp. 85-96, 2014.

[12] Reason J.T., Human Error, Cambridge University Press: Cambridge, 1990. doi: http:// dx.doi.org/10.1017/CBO9781139062367

[13] WHO, Global Status Report on Road Safety 2013: Supporting a Decade of Action, World Health Organization: Geneva, 2013.

[14] Van Elslande, P. \& Fouquet, K., L'erreur Urbaine : Défaillances, Facteurs et Contextes de Production des Accidents D’agglomération, Collections de l'Inrets: Arcueil, 2005.

[15] OECD, Road Accidents: On-site Investigations, Road Transport Research Program, OECD: Paris, 1988. 
[16] Van Elslande, P., Naing, C. \& Engel. R., Analysing human factors in road accidents. TRACE European Project, Deliverable 5.5, available at: www.trace-project.org (accessed: 15 April 2015).

[17] Van Elslande, P. Fournier, J.-Y. \& Jaffard M., Influence of cannabis on fatal traffic crash: a detailed analysis, Transportation Research Record, 2281, pp. 43-50, 2012. doi: http://dx.doi.org/10.3141/2281-06

[18] Landis, J.R. \& Koch, G.G., The measurement of observer agreement for categorical data. Biometrics, 33(1), pp. 159-174, 1977. doi: http://dx.doi.org/10.2307/2529310

[19] Jaffard, M. \& Van Elslande, P., Typical human errors in traffic accidents involving powered two-wheelers (Chapter 9). Advances in Traffic Psychology, eds. M. Sullman \& L. Dorn, International Association for Analytical Psychology: Ashgate, pp. 95-104, 2012

[20] Clabaux, N., Prevention of traffic accidents involving powered two-wheelers in urban areas: prototypical accident scenarios and prospects for the planning and design of the urban road infrastructures, Proceedings of the European Transport Conference 2007, Leeuwenhorst, 2007.

[21] ACEM, Motorcycle Accident In-Depth Study MAIDS: In-depth investigations of accidents involving powered two wheelers: Final report 2.0, ACEM: Brussels, 2009.

[22] Van Elslande, P., Fournier, J.-Y., \& Jaffard, M., In-depth analysis of road crashes involving powered two-wheelers. Work, 41, pp. 5871-5873, 2012.

[23] de Craen S., Doumen, M., Bos, N. \& van Norden, Y., The roles of motorcyclists and car drivers in conspicuity-related motorcycle crashes. SWOV : Leidschendam, 2011.

[24] Brenac, T., Clabaux, N., Perrin, C. \& Van Elslande, P., Motorcyclist conspicuity-related accidents in urban areas: a speed problem? Advances in Transportation Studies, 8, pp. 23-29, 2005.

[25] Radin Umar, R.S., Mackay, M. \& Hills, B., Multivariate analysis of motorcycle accidents and the effects of exclusive motorcycle lanes in Malaysia. Journal of Crash Prevention and Injury Control, 2(1), pp. 11-17, 2000. doi: http://dx.doi. org/10.1080/10286580008902549

[26] Daniels, S., Brijs, T., Nuyts, E. \& Wets, G., Explaining variation in safety performance of roundabouts. Accident Analysis and Prevention, 42, pp. 393-402, 2010. doi: http:// dx.doi.org/10.1016/j.aap.2009.08.019

[27] OECD, Towards Zero: Ambitious Road Safety Targets and the Safe System Approach, OECD: Paris, 2008. 